\title{
ISOLASI DAN IDENTIFIKASI SENYAWA FLAVONOID FRAKSI ETIL ASETAT EKSTRAK DAUN AFRIKA (Vernonia amygdalina Del.)
}

\author{
Ni Ketut Esati*, I Putu Eka Budiarta, Kadek Duwi Cahyadi, Gusti Ayu Dewi \\ Lestari \\ Sekolah Tinggi Farmasi Mahaganesha \\ *Email: esati0110@gmail.com
}

Artikel diterima: 26 Agustus 2021; Disetujui: 28 September 2021

DOI: https://doi.org/10.36387/jiis.v6i2.741

\begin{abstract}
ABSTRAK
Daun afrika (Vernonia amygdalina Del.) dilaporkan memiliki aktivitas sebagai antimalaria, antibakteri, antikanker, antioksidan, dan lainnya. Hal ini erat kaitannya dengan kandungan metabolit sekunder didalamnya yaitu flavonoid. Jadi tujuan dari penelitian ini yaitu mengisolasi dan mengidentifikasi senyawa flavonoid yang terkandung dalam daun afrika yang dipetik langsung di daerah Tabanan, Bali, dengan tahapan penelitiannya meliputi: maserasi daun afrika dengan pelarut etanol 96\%; fraksinasi ekstrak sehingga diperoleh fraksi etil asetat; pemisahan, isolasi, dan pemurnian senyawa flavonoid pada fraksi etil asetat; serta identifikasi senyawa flavonoid menggunakan metode spektrofotometri Ultra Violet-Visible (UV-Vis) dan Infrared (IR).

Dari hasil penelitian ini didapatkan rendemen ekstrak etanol sebanyak 3,693\%. Dalam ekstrak etanol daun afrika mengandung alkaloid, flavonoid, senyawa fenol, steroid, dan saponin. Hasil fraksinasi diperoleh fraksi n-heksana sebanyak 2,57 gram, fraksi etil asetat 0,53 gram, dan fraksi air sebanyak 3,02 gram. Fraksi etil asetat ekstrak etanol daun afrika ini teridentifikasi mengandung flavonoid golongan flavon dan flavonol, yang ditunjukkan adanya gugus $\mathrm{O}-\mathrm{H}, \mathrm{C}-$ $\mathrm{H}$ alifatik, $\mathrm{C}=\mathrm{O}, \mathrm{C}=\mathrm{C}$ aromatik, $\mathrm{C}-\mathrm{O}$ alkohol, dan $\mathrm{C}-\mathrm{H}$ aromatik.
\end{abstract}

Kata kunci: Daun afrika Bali, flavonoid, ekstrak etanol, fraksi etil asetat, spektrofotometri

\begin{abstract}
African leaves (Vernonia amygdalina Del.) are reported to have activity as anti-malarial, antibacterial, anticancer, antioxidant, and others. This is closely related to the secondary metabolite compounds, one of them is flavonoids. So that the purpose of this study, to isolated and identified the flavonoid compounds from african leaves. The plants were picked directly in the Tabanan area, Bali, with the stages of this study were maceration of african leaves with ethanol 96\%; after that, the isolation and purification of flavonoids in ethyl acetate fraction from extract of african leaves are doing. Then the isolate of flavonoid compounds are identified using Ultra Violet-Visible (UV-Vis) and Infrared (IR) spectrophotometer methods.
\end{abstract}


From the results of this study, the yield of ethanol extract was 3.693\%. African leaf ethanol extract contains alkaloids, flavonoids, phenolic compounds, steroids, and saponins. The results of the fractionation obtained $n$-hexane fraction as much as 2.57 grams, ethyl acetate fraction 0.53 grams, and water fraction was 3.02 grams. In ethyl acetate fraction ethanol extract of african leaf contained flavonoids of the flavone and flavonol groups, showed the presence of -OH groups, aliphatic $\mathrm{C}-\mathrm{H}, \mathrm{C}=\mathrm{O}$, aromatic $\mathrm{C}=\mathrm{C}, \mathrm{C}-\mathrm{O}$ alcohol, and aromatic $\mathrm{C}-\mathrm{H}$.

Keywords: African leaves from Bali, flavonoids, ethanol extract, ethyl acetate fraction, spectrophotometry

\section{PENDAHULUAN}

Tanaman obat adalah segala jenis tumbuhan yang diketahui mempunyai khasiat baik dalam membantu memelihara kesehatan maupun pengobatan suatu penyakit (Harmida dan Yuni, 2011). Tanaman obat sangat bermanfaat dalam dunia farmasi khususnya sebagai sumber bahan baku obat tradisional. Penggunaan obat tradisional di Indonesia semakin berkembang dikarenakan banyaknya temuan obat herbal terbaru yang dapat menyembuhkan penyakit (Utami dan Puspaningtyas, 2013). Salah satu tanaman yang menarik untuk diteliti adalah daun afrika (Vernonia amygdalina Del.) yang diduga sangat potensial untuk dikembangkan menjadi bahan baku obat tradisional.

Secara umum daun afrika (Vernonia amygdalina Del.) merupakan salah satu famili dari
Asteraceae. Daun afrika memiliki banyak manfaat dalam pengobatan tradisional dilihat dari penelitian sebelumnya, daun afrika ini memiliki efek maupun aktivitas seperti efek antiparasit, antimalaria, antihelmentik, antivirus, antikanker, antikoagulan dan antithrombik, analgesik dan antipiretik, antiinflamasi, antioksidan, antidiabetik, dan antioksidan (Yeap, dkk. 2010). Aktivitas biologis suatu ekstrak tanaman yang sangat erat kaitannya dengan senyawa metabolit sekunder yang dikandungnya. Salah satu metabolit sekunder yang memiliki peranan besar terhadap khasiat dari daun afrika adalah flavonoid (Jack, 2012).

Beberapa penelitian telah dilakukan terkait daun afrika, seperti yang dilakukan oleh Sukmawati, dkk. (2017) melalukan skrining fitokimia terhadap kandungan metabolit sekunderdari ekstrak daun afrika asal 
Jurnal Ilmiah Ibnu Sina, 6(2), Oktober 2021, 350-360

p-ISSN: 2502-647X; e-ISSN: 2503-1902

Ternate; Mashunah, dkk. (2020) lanjut tentang kandungan flavonoid mengisolasi senyawa steroid dari daun afrika asal Bali. Penelitian ekstrak n-heksana daun afrika; serta dilakukan dengan mengekstraksi daun Kharimah, dkk. (2016) mengidentifikasi keberadaan senyawa flavonoid secara kromatografi dalam daun afrika (berasal dari tanaman Jawa Barat) yang diekstraksi secara refluks (ekstraksi secara panas).

Diketahui bahwa kualitas senyawa aktif yang terkandung di dalam tanaman obat akan dipengaruhi oleh kondisi lahan, iklim, dan keadaan di lingkungan tempat hidup tanaman tersebut (Katno dan Pramono, 2008). Hal ini dipertegas juga oleh Sholekah (2017), bahwa metabolit sekunder terbentuk dari metabolit primer melalui berbagai jalur metabolisme yang dipengaruhi oleh beberapa faktor lingkungan. Faktor tersebut seperti cahaya, suhu, $\mathrm{pH}$, ketinggian tempat, dan temperatur yang akan berpengaruh terhadap kandungan fitokimianya. Kandungan fitokimia seperti flavonoid dan beta karoten dari suatu tanaman tentunya juga akan berbeda pada setiap wilayah dipengaruhi oleh faktor lingkungan tersebut.

Berdasarkan uraian diatas, peneliti melakukan penelitian lebih

\section{METODE PENELITIAN}

\section{Bahan}

Bahan-bahan yang digunakan adalah ekstrak daun afrika, etanol $96 \%$ (CALMO MEDICAL), kloroform, $\mathrm{H}_{2} \mathrm{SO}_{4}$, pereaksi mayer, asam klorida pekat, amil alkohol (EMSURE), $\mathrm{NaOH}, \mathrm{FeCl}_{3}$, pereaksi Lieberman buchard, $\mathrm{HCl} 2 \mathrm{M}$, akuades, etil asetat (BRATACHEM), n-heksana (BRATACHEM), asam asetat glasial (EMSURE), metanol, n-butanol, $\mathrm{AlCl}_{3}$.

Alat

Alat-alat yang digunakan pada penelitian ini yaitu peralatan gelas 
Jurnal Ilmiah Ibnu Sina, 6(2), Oktober 2021, 350-360

p-ISSN: 2502-647X; e-ISSN: 2503-1902

(IWAKI), pipa kapiler, bejana elusi KLT (CAMAG), kolom kromatografi, sentrifugator (IPC), oven (memmert), spektrofotometer UV-Vis (Thermo Spektro Genesis 10V-Vis), spektrofotometer Infrared (IRPrestige21 SHIMADZU), plat KLT (Merck TLC Silika gel GF60 $\mathrm{F}_{254}$ ).

\section{Ekstraksi dan Fraksinasi}

Simplisia daun afrika kering yang telah diekstraksi secara maserasi dengan etanol $96 \%$ diperoleh ekstrak kenal etanol. Ekstrak kental tersebut selanjutnya difraksinasi dengan pelarut n-heksana, etil asetat, dan air. Fraksi etil asetat ekstrak etanol daun afrika digunakan pada langkah selanjutnya.

\section{Pengujian flavonoid pada fraksi etil} asetat dengan Kromatografi Lapis Tipis (KLT)

Fraksi etil asetat yang diperoleh dari hasil fraksinasi, dianalisis menggunakan metode KLT dengan larutan pengembang (eluen) yaitu nbutanol-asam asetat glasial-air (BAA) perbandingan 4:1:5. Plat hasil elusi dideteksi di bawah lampu UV $254 \mathrm{~nm}$ dan $365 \mathrm{~nm}$ kemudian dilakukan penampakan bercak menggunakan uap amonia. Adanya flavonoid pada panjang gelombang $254 \mathrm{~nm}$ akan terjadi perubahan warna biru tua dan panjang gelombang $365 \mathrm{~nm}$ terlihat fluoresensi warna kuning, biru, atau hijau (Endang, 2014).

\section{Pemisahan senyawa flavonoid pada} fraksi etil asetat secara kromatografi kolom

Sebanyak 0,2g fraksi etil asetat dilarutkan dengan sedikit eluen (etil asetat). Setelah itu dimasukan kedalam kolom dengan perlahan sambil kran dibuka dengan kecepatan aliran kirakira $1 \mathrm{~mL} / \mathrm{menit}$. Proses elusi dilakukan menggunakan pelarut dengan kepolaran yang semakin meningkat, yaitu yaitu n-heksana $100 \%$ (2 kali), n-heksana : etil asetat (8:2), (6:4), (4:6), (2:8) etil asetat 100\%, etil asetat:metanol (1:1), metanol $\quad 100 \% \quad$ masing-masing sebanyak $25 \mathrm{~mL}$ (sekali). Eluat yang diperoleh ditampung dan diuji secara KLT, eluat yang memiliki pola noda dan nilai Rf yang sama, dikumpulkan dalam fraksi yang sama.

\section{Isolasi flavonoid menggunakan} kromatografi lapis tipis preparatif (KLTP)

Fraksi yang positif mengandung flavonoid selanjutnya dipreparatif. 
Jurnal Ilmiah Ibnu Sina, 6(2), Oktober 2021, 350-360

p-ISSN: 2502-647X; e-ISSN: 2503-1902

Eluen yang digunakan n-butanol : dengan spektrofotometer IR asam asetat glasial : air (4:1:5). Pita menggunakan kalium bromida (KBr) hasil KLTP dikerok dan dilarutkan yang digerus bersama sampel, lalu dalam pelarut metanol, kemudian diukur serapannya.

disentrifugasi untuk mengendapkan silikanya sehingga diperoleh isolat.

\section{Pemastian kemurnian isolat dengan}

KLT multi eluen dan pengujian dengan pereaksi kimia

Isolat yang diduga mengandung flavonoid dielusi menggunakan dua macam fase gerak dengan perbandingan yang berbeda dengan kepolaran tiap eluen berbeda yaitu butanol : asam asetat glasial : air (7:0,5:0,5) dan butanol : asam asetat galsial : etanol (6:1:0,5). Bercak tunggal yang dihasilkan menandakan bahwa isolat yang diperoleh merupakan senyawa tunggal atau murni. Tahap selanjutnya dilakukan pengujian dengan pereaksi kimia yaitu dengan uji $\mathrm{NaOH} 10 \%$ dan uji wilsttater.

\section{Identifikasi flavonoid menggunakan spektrofotometer UV-Vis dan IR}

Isolat positif flavonoid di analisis dengan metode spektrofotometri UVVis dengan penambahan perekasi geser $\mathrm{NaOH} 2 \mathrm{M}, \mathrm{HCl}, \mathrm{NaOAc}$, $\mathrm{NaOAc} / \mathrm{H}_{3} \mathrm{BO}_{3}$. Sedangkan pengujian

\section{HASIL DAN PEMBAHASAN}

\section{Ekstraksi simplisia}

Hasil ekstraksi yang diperoleh kemudian dipekatkan, dan diperoleh ektrak kental etanol daun afrika sebanyak 27,70 gram. Ekstrak kental yang diperoleh dihitung persen rendemen ekstrak dan didapatkan hasil seperti pada Tabel 1.

Tabel 1. Persen rendemen ekstrak etanol $96 \%$ daun afrika

$\begin{array}{cccc} & \text { Berat } & \text { Berat } & \text { \%rendemen } \\ \text { Sampel } & \text { Sampel } & \text { Ekstrak } & (\text { b/b) }\end{array}$

(g) (g)

\section{Ekstrak}

etanol

daun $\quad 750 \quad 27,70 \quad 3,693$

afrika

Dilihat pada tabel diatas, didapatkan hasil persen rendemen ekstrak etanol daun afrika sebesar $3,693 \%$. Nilai rendemen yang diperoleh dipengaruhi oleh waktu ekstraksi. Waktu ekstrasi yang semakin lama menyebabkan semakin lama kontak antara padatan dengan 
Jurnal Ilmiah Ibnu Sina, 6(2), Oktober 2021, 350-360

p-ISSN: 2502-647X; e-ISSN: 2503-1902

pelarut yang akan memperbanyak jumlah sel yang pecah dan bahan aktif yang terlarut, sehingga kemungkinan nilai rendemen yang diperoleh kecil (Wahyuni dan Widjanarko, 2015).

\section{Fraksinasi dan kromatografi lapis} tipis (KLT)

Dari proses fraksinasi akan diperoleh tiga fraksi yaitu fraksi nheksana, fraksi etil asetat, dan fraksi air. Dari ketiga fraksi yang diperoleh, selanjutnya diuapkan menggunakan penangas air pada suhu $50^{\circ} \mathrm{C}$ hingga memperoleh ekstrak kental. Hasil ekstrak kental yang diperoleh dari hasil penguapan yaitu fraksi n-heksana sebanyak 2,57gram, fraksi etil asetat sebanyak 0,53gram, dan fraksi air sebanyak 3,02gram. Pada penelitian ini akan digunakan fraksi etil asetat untuk tahap selanjutnya yaitu identifikasi senyawa flavonoid dengan metode KLT.

Pengujian flavonoid dengan KLT pada penelitian ini menunjukkan hasil yang positif mengandung flavonoid, seperti terlihat pada Gambar 1. Ketiga fraksi mengandung flavonoid ditandai dengan sampel (b, c, dan d) memiliki Rf yang sama dengan pembanding kuersetin, dan pada plat KLT setelah disinari lampu UV dengan panjang gelombang 365 $\mathrm{nm}$ terlihat fluoresensi biru dan kekuningan, sesuai dengan pustaka (Endang, 2014)

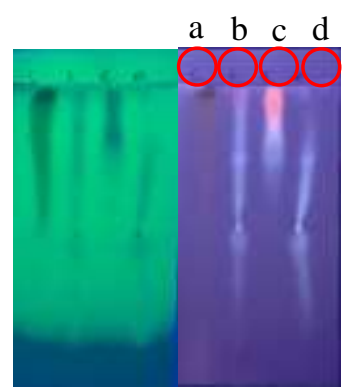

Gambar 1. Hasil pengujian fraksi dengan metode KLT pada lampu UV $254 \mathrm{~nm}$ dan $365 \mathrm{~nm}$

Keterangan : (a) kuersetin, (b) fraksi n-heksana, (c) fraksi etilasetat, (d) fraksi air

\section{Pemisahan senyawa flavonoid dengan metode KLT dan pengujian menggunakan pereaksi kimia}

Dari hasil kromatografi kolom, diperoleh eluat sebanyak 44 vial. Eluat-eluat tersebut diuji secara KLT yang memperlihatkan bercak yang sama dikumpulkan dan dilanjutkan pada proses isolasi flavonoid menggunakan KLT preparatif (KLTP). Dari hasil isolasi didapatkan penampakan pita berwarna merah dan biru yang masing-masing diberi label sebagai isolat merah dan biru. 
Jurnal Ilmiah Ibnu Sina, 6(2), Oktober 2021, 350-360

p-ISSN: 2502-647X; e-ISSN: 2503-1902

Kedua isolat yang diperoleh isolat yang ditandai dengan terjadinya dipastikan kemurnian menggunakan perubahan warna kuning kecoklatan metode KLT multi eluen. Pada pengujian ini menghasilkan hanya satu bercak, sehingga isolat dapat dikatakan murni secara KLT, dapat dilihat pada Tabel 2 dan Tabel 3.

Tabel 2. Hasil uji kemurnian isolat merah dengan metode KLT

\begin{tabular}{|c|c|c|c|}
\hline \multirow{2}{*}{ Fase gerak } & \multicolumn{2}{|c|}{$\begin{array}{c}\text { Penampakan } \\
\text { noda lampu Uv }\end{array}$} & \multirow{2}{*}{$\begin{array}{c}\text { Harga } \\
\mathbf{R} f\end{array}$} \\
\hline & $254 \mathrm{~nm}$ & $\begin{array}{l}365 \\
\mathrm{~nm}\end{array}$ & \\
\hline $\begin{array}{l}\text { Butanol : } \\
\text { asam asetat } \\
\text { glasial : air } \\
(7: 0,5: 0,5)\end{array}$ & - & $\begin{array}{c}\text { Merah } \\
\text { Biru }\end{array}$ & $\begin{array}{l}0,875 \\
0,938\end{array}$ \\
\hline $\begin{array}{c}\text { Butanol : } \\
\text { asam asetat } \\
\text { glasial : } \\
\text { etanol } \\
(6: 1: 0,5)\end{array}$ & - & $\begin{array}{c}\text { Merah } \\
\text { Biru }\end{array}$ & $\begin{array}{l}0,875 \\
0,938\end{array}$ \\
\hline
\end{tabular}

\section{Keterangan : (-) tidak terlihat} penampakan noda yang jelas

Tabel 3. Hasil uji kemurnian isolat biru dengan metode KLT

\begin{tabular}{|c|c|c|c|}
\hline \multirow{2}{*}{$\begin{array}{c}\text { Fase } \\
\text { gerak }\end{array}$} & \multicolumn{2}{|c|}{$\begin{array}{c}\text { Penampakan } \\
\text { noda lampu Uv }\end{array}$} & \multirow{2}{*}{$\begin{array}{l}\text { Harga } \\
\mathbf{R} f\end{array}$} \\
\hline & $254 \mathrm{~nm}$ & $365 \mathrm{~nm}$ & \\
\hline $\begin{array}{l}\text { Butanol : } \\
\text { asam asetat } \\
\text { glasial : air } \\
(7: 0,5: 0,5)\end{array}$ & - & Biru & 0,938 \\
\hline $\begin{array}{l}\text { Butanol : } \\
\text { asam asetat } \\
\text { glasial : } \\
\text { etanol } \\
(6: 1: 0,5)\end{array}$ & - & Biru & 0,938 \\
\hline
\end{tabular}

Keterangan : (-) tidak terlihat

penampakan noda yang jelas

\section{Pengujian isolat flavonoid dengan pereaksi kimia}

$$
\text { Pada uji } \mathrm{NaOH} \quad 10 \%
$$
menunjukan hasil positif pada kedua

diindikasikan isolate mengandung senyawa flavonoid jenis Flavanon, flavon, flavonol, flavonolol (Venkataraman, 1962).

Pada uji wilsttater juga menunjukan hasil positif yaitu pada isolat merah ditandai dengan terjadinya perubahan warna menjadi kuning yang artinya positif mengandung isoflavon dan pada isolat biru terjadinya perubahan warna menjadi kuning-jingga yang artinya positif mengandung flavonoid jenis flavon (Venkataraman, 1962).

\section{Identifikasi flavonoid menggunakan} metode spektrofotometri UV-Vis

Berdasarkan spektrum yang diperoleh menunjukan isolat terletak pada 310,131 (pita I) dan 239,382 (pita II) untuk isolat merah. Sedangkan isolate biru pada 310,61 (pita I) dan 259,189 (pita II). Penentuan spektrum menggunakan penambahan pereaksi geser disajikan pada Tabel 4.

Pada isolat merah, setelah penambahan pereaksi geser $\mathrm{NaOH} 2 \mathrm{M}$ terjadi pergeseran batokromik pada pita I sebesar 50,809 nm yang artinya terdapat dugaan adanya senyawa 
Jurnal Ilmiah Ibnu Sina, 6(2), Oktober 2021, 350-360

p-ISSN: 2502-647X; e-ISSN: 2503-1902

flavon dan flavonol, setelah menghasilkan pergeseran hipsokromik penambahan pereaksi geser $\mathrm{NaOAc}$ terjadi pergeseran pada pita II yang menunjukkan pergeseran ke panjang gelombang yang lebih kecil (hipsokromik) sebesar 5,341 nm yang artinya terdapat dugaan adanya senyawa flavonoid yaitu flavon, flavonol, dan isoflavon, dan setelah penambahan $\mathrm{H}_{3} \mathrm{BO}_{3}$ pada isolat merah pada pita I menunjukkan pergeseran sebesar 32,771 yang artinya terdapat dugaan adanya senyawa flavonoid yaitu flavon, flavonol, auron, dan khalkon.

Tabel 4. Panjang gelombang maks $(\mathrm{nm})$ isolat setelah penambahan pereaksi geser

\begin{tabular}{ccc}
\hline \multirow{2}{*}{$\begin{array}{c}\text { Panjang gelombang } \\
\text { maks }(\mathbf{n m}) \text { dengan } \\
\text { penambahan } \\
\text { pereaksi geser }\end{array}$} & \multicolumn{2}{c}{ Isolat } \\
\cline { 2 - 3 } & Merah & Biru \\
\hline $\mathrm{NaOH} 2 \mathrm{M}$ & 241,076 & 269,131 \\
\hline $\mathrm{NaOAc}^{2} \mathrm{Ac}$ & 234,041 & - \\
\hline $\mathrm{H}_{3} \mathrm{BO}_{3}$ & 240,239 & - \\
\hline $\mathrm{NaOAC}+\mathrm{H}_{3} \mathrm{BO}_{3}$ & - & 255,057 \\
\hline $\mathrm{Pada}$ isolat & biru, & setelah
\end{tabular}

penambahan geser $\mathrm{NaOH} 2 \mathrm{M}$ terjadi pergeseran pada pita I yang menunjukkan pergeseran sebesar 45,884 $\mathrm{nm}$ yang artinya terdapat dugaan adanya senyawa flavonoid jenis flavon dan flavonol, sedangkan setelah $\mathrm{NaOAc}+\mathrm{H}_{3} \mathrm{BO}_{3}$ pada pita II sebesar 4,162 nm yang kemungkinan terjadi tidak terdapat senyawa flavonoid.

Identifikasi flavonoid menggunakan metode spektrofotometri infrared (IR)

Identifikasi flavonoid dengan spektrofotometri infrared dilakukan untuk mengetahui gugus fungsi yang terdapat dalam isolat murni flavonoid. Sebanyak 0,1 gram kalium bromida $(\mathrm{KBr})$ lalu digerus sampai halus dan diletakan pada sample base dan diukur serapannya. Hal ini bertujuan untuk melihat daerah serapan pada standar $\mathrm{KBr}$ sehingga setelah diketahui serapan standarnya bisa dibandingkan dengan serapan setelah diisi sampel. Hasil pengukuran kedua isolat menggunakan spektrofotometri infrared dapat dilihat pada Gambar 1 dan Gambar 2.

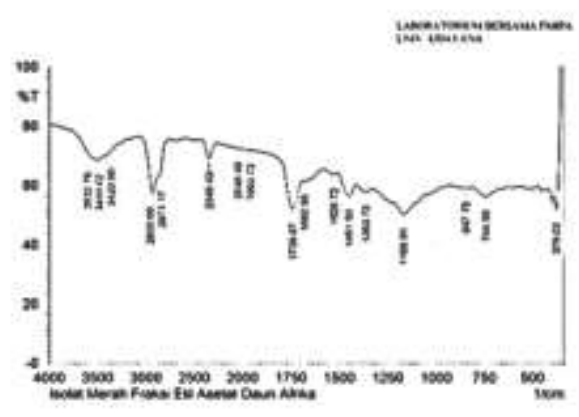

Gambar 1. Spektrum infrared isolat merah 


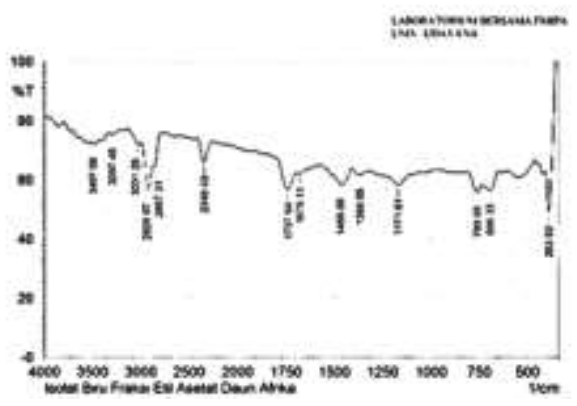

Gambar 2. Spektrum infrared isolat biru

Berdasarkan analisis spektrum infrared, menunjukan adanya beberapa gugus fungsi. Hasil analisis isolat merah yaitu adanya serapan melebar pada 3420,90 dan 3499,02 $\mathrm{cm}^{-1}$ dan pada isolat biru adanya serapan pada 3031,$26 ; 3297,45$; dan 3497,09 yang diduga adalah serapan dari gugus $\mathrm{O}-\mathrm{H}$, kemudian serapan gugus $\mathrm{C}-\mathrm{H}$ alifatik yang tajam muncul di daerah 2871,17 dan 2930,00 pada isolat merah, sedangkan pada isolat biru serapan muncul pada daerah 2867,31 dan 2928,07. Hal ini didukung dari hasil penelitian oleh Akbar (2010) bahwa serapan pada bilangan gelombang $2927,36 \mathrm{~cm}^{-1}$ menunjukan vibrasi gugus $\mathrm{C}-\mathrm{H}$ didalam gugus $\mathrm{C}-\mathrm{H}$ alifatik. Adanya gugus karbonil $(\mathrm{C}=\mathrm{O})$ sebagai ciri umum senyawa golongan flavonoid Sukadana (2010) yang diindikasikan oleh adanya serapan pada daerah bilangan gelombang 1616,35. Serapan gugus $\mathrm{C}=\mathrm{C}$ aromatik muncul pada daerah bilangan gelombang 1451,5 dan 1526,72 pada isolat merah dan daerah bilangan gelombang 1468,86 untuk isolat biru, kemudian vibrasi gugus $\mathrm{C}-\mathrm{O}$ dalam senyawa fenol menghasilkan pita kuat di daerah $1260-1000 \mathrm{~cm}^{-1}$ dan pada isolat merah serapan C-O muncul pada daerah bilangan gelombang 1168,91 dan pada isolat biru muncul pada panjang gelombang 1171,81 . Adanya gugus $\mathrm{C}$ $\mathrm{H}$ aromatik ditunjukan dengan munculnya serapan isolat merah pada bilangan gelombang 744,55 dan 847,75 sedangkan pada isolat biru muncul serapan pada bilangan gelombang 696,33 dan 760,95. Adanya gugus fungsi $\mathrm{O}-\mathrm{H}, \quad \mathrm{C}-\mathrm{H}$ alifatik, $\mathrm{C}=\mathrm{C}$ aromatik dan $\mathrm{C}-\mathrm{O}$ mengindikasikan isolat ini suatu senyawa flavonoid. Hal ini diperkuat berdasarkan hasil penelitian yang dilakukan oleh Akbar (2010) sesuai dengan hasil spektrum infrared adanya gugus fungsi $\mathrm{O}-\mathrm{H}, \mathrm{C}=\mathrm{O}, \mathrm{C}-\mathrm{O}, \mathrm{C}=\mathrm{C}$ aromatik, dan C-H alifatik yang mendukung bahwa isolatnya positif suatu senyawa flavonoid. 
Jurnal Ilmiah Ibnu Sina, 6(2), Oktober 2021, 350-360

p-ISSN: 2502-647X; e-ISSN: 2503-1902

\section{KESIMPULAN}

Fraksi etil asetat ekstrak etanol daun afrika (vernonia amygdalina Del.) mengandung senyawa flavonoid jenis flavon dan flavonol yang dipertegas menggunakan pengujian flavonoid dengan pereaksi kimia.

\section{UCAPAN TERIMA KASIH}

Terima kasih kepada semua pihak yang tidak dapat disebutkan satu-persatu, yang telah membantu dalam proses penelitian dan penyusunan naskah ini.

\section{DAFTAR PUSTAKA}

Akbar, H. and Rizki (2010) 'Isolasi dan Identifikasi Golongan Flavonoid Daun Dandang Gendis (Clinacanthus nutans) Berpotensi Sebagai Antioksidan', Departemen Kimia, Fakultas MIPA. Institut Pertanian Bogor.

Endang, H. (2014) 'Analisis Fitokimia', Penerbit Buku Kedokteran. Jakarta : EGC.

Harmida, S. and Yuni, V. F. (2011) 'Studi Etnofitomedika di Desa Lawang Agung Kecamatan Mulak Ulu Kabupaten Lahat Sumatera Selatan', Jurnal Penelitian Sains, 14(1), pp. 42-46.

Jack (2012) 'Synthesis of Antidiabetic Flavonoids and Their
Derivative', Medical Research, p. 180.

Katno and Pramono, S. (2008) 'Tingkat Manfaat dan Keamanan Tanaman Obat dan Obat Tradisional', Fakultas Farmasi Universitas Gajah Mada, Yogyakarta, p. 14.

Kharimah, ZN, Lukmayani, Y. dan

Syafnir, L. 2016. 'Identifikasi Senyawa Flavonoid pada Ekstrak dan Fraksi Daun Afrika (Vernonia amygdalina Del.)'.Prosiding Farmasi,2(2), pp. 703-709

Mashunah, E., Erwin., Sitorus, S. 2020. 'Isolasi dan Identifikasi Steroid dari Ekstrak NHeksana Daun Afrika (Vernonia amygdalina Del.)'. KOVALEN : Jurnal Riset Kimia, 18-22.

Sholekah, F. F. (2017) 'Perbedaan Ketinggian Tempat Terhadap Kandungan Flavonoid dan Beta Karoten Buah Karika (Carica pubescens) Daerah Dieng Wonosobo', Prosiding Seminar Nasional. Jurusan Pendidikan Biologi. Fakultas MIPA, Universitas Negeri Yogyakarta., p. 8.

Sukadana, I. M. (2010) 'Aktivitas Antibakteri Senyawa Flavonoid dari Kulit Akar Awar-awar (Ficus Septica).', Jurusan Kimia FMIPA Universitas Udayana, 4(1), pp. 63-67.

Sukmawati, 2017. 'Potensi Senyawa Flavonoid Daun Afrika Asal Ternate sebagai Antioksidan'. 
Jurnal Ilmiah Ibnu Sina, 6(2), Oktober 2021, 350-360

p-ISSN: 2502-647X; e-ISSN: 2503-1902

Makassar : Fakultas Farmasi

Indonesia. 2(2). 53-61.

Utami, P. and Puspaningtyas, D. E. (2013) 'The Miracle of Herbs', Jakarta: PT AgroMedia Pustaka.

Wahyuni, D. T. and Widjanarko, S. B. (2015) 'Pengaruh Jenis Pelarut dan Lama Ekstraksi Terhadap Ekstrak Karotenoid Labu Kuning dengan Metode Gelombang Ultrasonik', Jurusan Teknologi Hasil
Pertanian. FTP Universitas Brawijaya. Malang. Jurnal Pangan dan Agroindustri, Vol. 3(No. 2), pp. 390-401.

Yeap, S. K. et al. (2010) 'Vernonia amygdalina an ethnoveterinary and ethnomedical used green vegetable with multiple bioactivities.', J.Med.Plant research., 4(25), pp. 27872812. 